Department of Occupational and Environmental Medicine, University Hospital, Umeå, Sweden

B Rudel

\section{Department of}

Occupational and

Environmental

Medicine, Centre for

Public Health

Sciences, Linköping,

Sweden

B Rudell

Volvo Technological

Development

Corporation,

Gothenburg, Sweden

U Wass

Department of

Pathology, University

Hospital, Umeå,

Sweden

P Hörstedt

Department of

Chemistry, National

Institute for Working

Life, Umeå, Sweden

J-O Levin

R Lindahl

A-L Sunesson

Department of

Occupational and

Environmental

Medicine, University

of Umeå, Umeå

Sweden

J-O Levin

Department of Genetic and Cellular

Toxicology, Wallenberg Laboratory, Stockholm

University, Stockholm,

Sweden

U Rannug

Department of Otorhinolaryngology,

University Hospital,

Umeå, Sweden

Y Östberg

Department of Respiratory Medicine and Allergy, University Hospital, Umeå,

Sweden

T Sandström

Correspondence to:

Dr Bertil Rudell,

Department of Occupational and Environmental

Medicine, Centre for Public

Health Sciences, S-581 85

Linköping, Sweden.

Telephone 004613221448

fax 004613145831 ; email

Bertil.Rudell@lio.se

Accepted 12 November 1998

\title{
Efficiency of automotive cabin air filters to reduce acute health effects of diesel exhaust in human subjects
} B Rudell, U Wass, P Hörstedt, J-O Levin, R Lindahl, U Rannug, A-L Sunesson,
Y Östberg, T Sandström

\begin{abstract}
Objectives-To evaluate the efficiency of different automotive cabin air filters to prevent penetration of components of diesel exhaust and thereby reduce biomedical effects in human subjects. Filtered air and unfiltered diluted diesel exhaust (DDE) were used as negative and positive controls, respectively, and were compared with exposure to DDE filtered with four different filter systems.
\end{abstract}

Methods-32 Healthy non-smoking subjects (age 21-53) participated in the study. Each subject was exposed six times for 1 hour in a specially designed exposure chamber: once to air, once to unfiltered DDE, and once to DDE filtered with the four different cabin air filters. Particle concentrations during exposure to unfiltered DDE were kept at $300 \mu \mathrm{g} / \mathrm{m}^{3}$. Two of the filters were particle filters. The other two were particle filters combined with active charcoal filters that might reduce certain gaseous components. Subjective symptoms were recorded and nasal airway lavage (NAL), acoustic rhinometry, and lung function measurements were performed.

Results-The two particle filters decreased the concentrations of diesel exhaust particles by about half, but did not reduce the intensity of symptoms induced by exhaust. The combination of active charcoal filters and a particle filter significantly reduced the symptoms and discomfort caused by the diesel exhaust. The most noticable differences in efficacy between the filters were found in the reduction of detection of an unpleasant smell from the diesel exhaust. In this respect even the two charcoal filter combinations differed significantly. The efficacy to reduce symptoms may depend on the abilities of the filters investigated to reduce certain hydrocarbons. No acute effects on NAL, rhinometry, and lung function variables were found.

Conclusions-This study has shown that the use of active charcoal filters, and a particle filter, clearly reduced the intensity of symptoms induced by diesel exhaust. Complementary studies on vehicle cabin air filters may result in further diminishing the biomedical effects of diesel exhaust in subjects exposed in traffic and workplaces.

(Occup Environ Med 1999;56:222-231)
Keywords: diesel exhaust; exposure chamber; vehicle cabin air filters; symptoms; humans

Particulate matter, according to the World Health Organisation (WHO) and the United Nations Environment Program, is the most serious air pollution problem globally. ${ }^{1}$ Air pollutants, and in particular particulate matter, have been strongly associated with adverse affects on respiratory health. Airway symptoms, exacerbations of asthma and chronic obstructive pulmonary disease (COPD), emergency department visits, and hospital admissions have been associated with increases in particulate air pollution. This has also been shown for cardiac and respiratory deaths rates. ${ }^{2-8}$ Particles $<2.5 \mu \mathrm{m}\left(\mathrm{PM}_{2.5}\right)$, such as diesel exhaust particles, seem to be associated with even greater health risks than $\mathrm{PM}_{10}{ }^{9}{ }^{10}$

Diesel exhaust is a major contributor to ambient air particles in places with high traffic intensity. The exhaust also includes many gaseous components- such as carbon monoxide (CO), nitric oxide (NO), nitrogen dioxide $\left(\mathrm{NO}_{2}\right)$, hydrocarbons (HCs), and aldehydes, and is well known to cause discomfort in exposed people. Subjects exposed to diesel exhaust in work situations have been reported to have increased prevalence of symptoms of the eyes, nose, and throat, and also have laboured breathing, coughing, phlegm, wheezing, and headache. ${ }^{11}{ }^{12}$ Lung function deterioration has been reported from exposure to diesel exhaust in a tunnel, garage, and ferries. $^{13-16}$

The effects on lung function and symptoms have been confirmed in recent standardised experimental exposure chamber studies that allowed controlled exposures to diluted diesel exhaust (DDE) in human subjects. ${ }^{17}{ }^{18}$ Diluted diesel exhaust has also been shown to be proinflammatory, causing inflammatory reactions in the lower airways of healthy subjects as reflected in bronchoalveolar lavage fluid and bronchial mucosal biopsies together with distortion in alveolar macrophage functions. ${ }^{19-21}$ In the upper airways, antioxidant concentrations in nasal lavage have been affected after exposure to diesel exhaust. ${ }^{22}$ Also diesel exhaust particles have recently been found to enhance IgE responses in the nasal mucosa of humans, ${ }^{23}$ similar to findings from animal studies. ${ }^{24}$

The number of diesel powered vehicles on the road is increasing in most countries. This is partly due to the robust and long lasting 
Table 1 The various exposure or test situations; air, unfiltered diluted diesel exhaust $(D D E)$, and $D D E$ filtered with the four different cabin air filters (the filter codes $6 C, 7 A$, $7 C$, and $8 A$ are internal industry product codes; $6 C$ and $7 A$ refer to particle filters; and $7 C$ and $8 A$ to filters with activated charcoal)

\begin{tabular}{lllll}
\hline $\begin{array}{l}\text { Test/ } \\
\text { exposure } \\
\text { situation }\end{array}$ & $\begin{array}{l}\text { Inlet of } \\
\text { fresh } \\
\text { filtered air }\end{array}$ & $\begin{array}{l}\text { Addition of } \\
\text { diluted diesel } \\
\text { exhaust }\end{array}$ & $\begin{array}{l}\text { Cabin filter } \\
\text { or filter } \\
\text { combination }\end{array}$ & Comment \\
\hline Air & Yes & No & No & Negative control \\
DDE & Yes & Yes & No & Positive control \\
Filter 1 & Yes & Yes & Yes & 7A (particle filter) \\
Filter 2 & Yes & Yes & Yes & 6C (particle filter) \\
Filter 3 & Yes & Yes & Yes & 6C (particle filter) +7C (charcoal filter) \\
Filter 4 & Yes & Yes & Yes & 6C (particle filter)+8A (charcoal filter) \\
\hline
\end{tabular}

technical properties of the engines, but also due to fuel economy and other factors. As diesel exhaust may cause several adverse biomedical effects, it is important to reduce these effects in those people who are exposed. Drivers of lorries, buses, cars, and heavy equipment vehicles are exposed to the exhaust through the air inlet of the vehicles. One alternative to reduce the exposure of drivers of vehicles to the various components in the exhaust is to use cabin filters in the ventilation systems. The cabin filter efficiency for inorganic gases, hydrocarbons, and smaller particles has generally not been high, and has been shown to vary considerably.

The aim of the present study was to evaluate the efficiency of different automotive cabin air filters to prevent penetration of components of diesel exhaust and thereby reduce biomedical effects in human subjects. Filtered air and unfiltered DDE were used as negative and positive controls, respectively, in comparison with exposure to DDE filtered with four different filter systems. The study used a specially designed exposure chamber and was based on earlier controlled studies of exposure to diesel exhaust.

\section{Subjects and methods}

Thirty two healthy non-smoking subjects (mean age 29, range 21-53, 15 men, 17 women) participated in the study. Sixteen had a clear history and positive skin prick tests consistent with seasonal allergic rhinoconjunctivitis to grass or tree pollen. All were asymptomatic and were investigated outside the pollen season. Subjects were otherwise healthy. To include both subjects who were and were not often exposed to diesel exhaust, 14 of the sub-

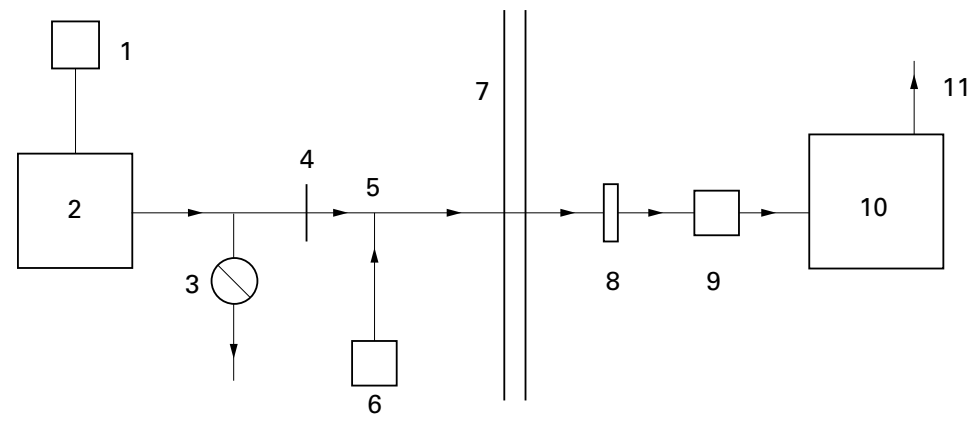

Figure 1 Experimental diesel exhaust system. The arrows show air and exhaust flow directions: (1) water loaded engine dynamometer; (2) diesel engine, Volvo TD 45; (3) exhaust shunt with the valve; (4) flexible diaphragm; (5) mixing of diesel exhaust and filtered air; (6) outdoor air inlet and particle filters; (7) wall between machinery hall and exposure hall; (8) iris diaphragm for adjusting the flow; (9) filter frame and cabin air filter to be studied; (10) exposure chamber $3 \times 3 \times 2.3 \mathrm{~m}$; (11) chamber evacuation. jects were bus drivers from the city, and 18 were students. The participants gave their informed consent and the study was approved by the Umeå University ethics committee.

\section{STUDY DESIGN}

Each subject was exposed six times: once to air, once to unfiltered DDE, and once to DDE filtered with the four different cabin air filters (table 1). The exposures lasted for 1 hour and the subjects were sitting on a chair during exposure to imitate a driving situation. The exposures were conducted in the exposure chamber shown in figure 1 , according to principles previously outlined. ${ }^{17-21}$ Air exposures were performed before the other exposures because diesel exhaust has a pronounced odour, which cannot be concealed. The order of the five different exposures to diesel exhaust was randomised. Each subject was only exposed to one exhaust a day and the interval between the exposures was 6 days. Subjective symptoms were recorded and nasal airway lavage (NAL), acoustic rhinometry, and lung function measurements were performed. Only the investigator handling the filter combinations knew the actual exposure sequence. This was not revealed until all analyses and statistics were completed.

During all exposures formaldehyde and particles were collected on different filters and $\mathrm{NO}_{2}, \mathrm{NO}, \mathrm{CO}$, and $\mathrm{HCs}$ were continuously analysed. Additional more detailed measurements of particles, aliphatic and aromatic hydrocarbons, and genotoxicity in Ames test with diesel exhaust particles were all performed once in the exposure chamber with air, DDE, and DDE with the four different cabin air filter combinations.

\section{Experimental system}

The experimental system has previously been described, ${ }^{17-21} 25$ but was developed further in this study (fig 1) to test different cabin air filters.

A computer linked to a water loaded engine dynamometer (Schenk NRD 3832, Germany) controlled the engine. Most of the exhaust was shunted away before it was diluted with filtered air. The air filter (fig 1) consisted of a combination of a prefilter and an absolute filter (model 1D-450-01/10, Camfil, Skärholmen, Sweden) with a particle reduction of $99.99 \%$ for $0.3 \mu \mathrm{m}$ particles. A radial fan (GTCentrivent, ABB Ventilation, Enköping, Sweden), with a variable flow to meet the varying pressure drops of the different cabin air filters, fed the air from outdoors through these two air filters. The tube (length $0.4 \mathrm{~m}$, diameter 100 $\mathrm{mm}$ ) from the shunt and dilutor was inserted into the tube (diameter $200 \mathrm{~mm}$ ) from the air intake to the exposure chamber $(3 \times 3 \times 2.3 \mathrm{~m})$. In the tube between the shunt and dilutor and the exposure chamber was an iris diaphragm to keep a constant flow of $70 \mathrm{l} / \mathrm{s}$ through the different cabin air filters. The distances from the mixing of diesel exhaust and air to the iris diaphragm, iris diaphragm to cabin filter frame, and cabin filter frame to exposure chamber were $1.9,0.75$, and $0.2 \mathrm{~m}$, respectively. The 
subjects could not see the filter frame with or without cabin filters due to an opaque cover.

There was no cabin filter in the frame when the subjects were exposed to just DDE or air.

Engine, load, speed, fuel, motor oil

The engine, a Volvo TD 45 model 1991, was connected to a water loaded engine dynamometer and it was operated at $1400 \mathrm{r} / \mathrm{m}(50 \%$ speed) and $30.6 \mathrm{~kW}$ (50\% load). The engine had four cylinders, four strokes, and a direct injected turbocharger. The displacement was $4.48 \mathrm{dm}^{3}$, bore $105.57 \mathrm{~mm}$, stroke $128 \mathrm{~mm}$, and compression ratio 15.6:1.

A Swedish standard diesel fuel D 10, (Preem Petroleum $\mathrm{AB}$ ) with a relatively high concentration of sulphur, was used. The main fuel characteristics were: 0.06 mass \% sulphur, centane number 50.7, and 10,50, and $95 \%$ boiling point at 211,239 , and $363^{\circ} \mathrm{C}$, respectively.

The motor oil was Mobil mineral oil $\mathrm{CD} / \mathrm{CE}$.

\section{Exhaust flow rates}

The exhaust flows in, and the flow to the shunting tube and to dilution were measured with the engine running, and flow from the engine was the sum of these. The exhaust flows from the engine, shunting, and to dilution, were standardised to $20^{\circ} \mathrm{C}$ and were 52.4 , 42.1 , and $10.3 \mathrm{l} / \mathrm{s}$, respectively. The flow of DDE-that is, air plus diesel exhaust to dilution through the different cabin filters in the filter frame, was $70 \mathrm{l} / \mathrm{s}$.

Instruments and analytical methods including the Ames test

All exposure measurements were done in the breathing zone of the subjects in the exposure chamber. Measurements in the additional cabin air filter tests were performed in the same way.

The concentrations of $\mathrm{NO}, \mathrm{NO}_{2}, \mathrm{CO}$, and $\mathrm{HCs}$ were continuously registered in the exposure chamber as previously described. ${ }^{17}{ }^{18} \mathrm{NO}$ and $\mathrm{NO}_{2}$ were analysed with a chemiluminescence instrument, CLD 700 AL ECO Physics AG (Dürnten, Schweiz). A Miran 1-A, an IR-instrument (Foxboro, East Bridgewater, MA, USA), was used for analysis of CO. The HCs were analysed with the FID-instrument, model 3-300 (JUM Engineering $\mathrm{GmbH}$, München, Germany) with a heated prefilter $\left(180^{\circ} \mathrm{C}\right)$ and calibrated with propane: $\mathrm{X}-\mathrm{Y}$ recorders were used.

Particles in the exposure chamber were collected on membrane filters (cellulose nitrate, pore size $0.8 \mu \mathrm{m}$; ADVAVTEC/MFS, Pleasanton, CA, USA) with a diameter of 25 $\mathrm{mm}$. The filters were weighed before and after the collection.

Formaldehyde was collected (about 200 $\mathrm{ml} / \mathrm{min}$ ) on glass fibre filters (diameter $13 \mathrm{~mm}$ ) impregnated with 2,4-dinitrophenylhydrazine and analysed with high performance liquid chromatography. ${ }^{26}$ Due to relatively low exposure concentrations of particles (mass) and formaldehyde the collection times of these compounds were increased and consequently the number of measurements was also reduced.

Additional vehicle cabin air filter tests were performed at separate occasions. Particles were analysed with a condensation particle counter, differential mobility particle sizer (DMPS), and scanning electron microscopy, as well as an Ames test. High performance liquid chromatography and gas chromatography-mass spectrometry (GC-MS) were used for hydrocarbon analysis. All tests were done on samples from one of each of the six test situations (table 1) as these analyses are extremely time and resource intensive.

Number of particles - Continuous registration of the number of submicron particles $/ \mathrm{cm}^{3}$ was obtained for 6 hours with a condensation particle counter, model 3022 (TSI, St Paul, MN, USA) as earlier published. ${ }^{17-19}$

The differential mobility particle sizer systemThe differential mobility particle sizer system, which includes a computer, condensation particle counter, and an electrostatic classifier, model 3071 (TSI St Paul, MN, USA), was used to measure the number of particles as a function of the particle size which was recently described. ${ }^{21}$ Particles from 0.017 to $0.9 \mu \mathrm{m}$ were recorded with a measuring time of $8 \mathrm{~min}$ utes. The computer system calculated the geometric mean electrical mobility equivalent diameter for the numbers of the particles in the exposure chamber.

Scanning electron microscopic analysis of DDE particles-There has been previous scanning electron microscopic analysis of DDE particles originating from idling trucks with and without a ceramic particle trap at the end of the tail pipe, collected on Poretics filters (polycarbonate; Poretics Products, Osmonics, Livemore, CA, USA) and Nuclepore filters (polycarbonate; Corning Separations, Acton, MA, USA) in the exposure chamber. ${ }^{17}{ }^{18} 21$ Diesel exhaust particles were collected for 5 minutes on Nuclepore filters (filter diameter $25 \mathrm{~mm}$, pore size $0.4 \mu \mathrm{m}$ ) in the exposure chamber. These Nuclepore filters were coated with 175 Ångstrom of gold by evaporation (Edwards E14 Vacuum Coating Unit, Edwards High Vacuum, Crawley, UK.), and were analysed in the scanning electron microscope, Leo 360 SEM (Leo Electron Microscopy, Cambridge, UK.) fitted with $\mathrm{LaB}_{6}$ emitter and operated at $20 \mathrm{kV}$ and $0^{\circ}$ tilt. $^{27}$ Randomly chosen areas were recorded at 5000 times magnification and stored on a PC. A Leica Qwin version 2.3 image analysis software (Leica Imaging Systems, Cambridge, UK) made all measurements. Particles in 25 areas $\left(10.557 \mu \mathrm{m}^{2}\right)$ from each sample were counted and measured for equivalent diameters $\geqslant 0.4 \mu \mathrm{m}$ with standard routines for particle measurements.

Acetaldehyde - Acetaldehyde hydrazone was previously described. ${ }^{28}{ }^{29}$ For sampling aldehydes, Waters Sep-Pak DNPH-Silica was used (Waters, Milford, MA, USA). In the exposure chamber six parallel samples were run at airflows of about $200 \mathrm{ml} / \mathrm{min}$ and the sampling time was 120 minutes. A high performance liquid chromatography system consisting of 
Table 2 Steady state concentrations during exposure to air, diluted diesel exhaust (DDE), and DDE filtered with the four different cabin air filters (values are mean (SD))

\begin{tabular}{|c|c|c|c|c|c|c|c|c|c|c|c|c|}
\hline $\begin{array}{l}\text { Exposurel } \\
\text { test } \\
\text { situation }\end{array}$ & NO ppm & $\mathrm{NO}_{2} p p m$ & $\begin{array}{l}\text { Particles * } \\
\mathrm{mg} / \mathrm{m}^{3}\end{array}$ & $\begin{array}{l}\text { Particlest } \\
\times 10^{6} / \mathrm{cm}^{3} \\
0.01-1 \mu \mathrm{m}\end{array}$ & $\begin{array}{l}\text { Particles } \\
\text { EMED† } \\
\mathrm{nm}\end{array}$ & $\begin{array}{l}\text { Particles } \times 10^{6} / \\
\mathrm{cm}^{2} \text { SEM } \dagger \\
\geqslant 0.4 \mu \mathrm{m}\end{array}$ & $C O p p m$ & $H C p p m$ & $\begin{array}{l}\text { Total } \\
\text { aliphatics } \\
+\mu g / m^{3}\end{array}$ & $\begin{array}{l}\text { Total } \\
\text { aromaticst } \\
\mu g / m^{3}\end{array}$ & $\begin{array}{l}\text { Formaldehyde } \\
\mu \mathrm{g} / \mathrm{m}^{3}\end{array}$ & $\begin{array}{l}\text { Acetaldehydet } \\
\mu \mathrm{g} / \mathrm{m}^{3}\end{array}$ \\
\hline Air & $<0.02$ & $<0.02$ & $<0.03$ & $<0.001$ & - & 0 & $<0.05$ & $<0.9$ & 4 & 11 & $<6$ & 5 \\
\hline DDE & $\begin{array}{l}11.0 \\
(0.13)\end{array}$ & $\begin{array}{l}0.7 \\
(0.04)\end{array}$ & $\begin{array}{l}0.29 \\
(0.03)\end{array}$ & 2.8 & 55 & 9.8 & $1.1(0.2)$ & $\begin{array}{l}1.4 \\
(0.07)\end{array}$ & 45 & 57 & $36(6)$ & 27 \\
\hline Filter 1 & $\begin{array}{l}11.0 \\
(0.13)\end{array}$ & $\begin{array}{l}0.7 \\
(0.05)\end{array}$ & $\begin{array}{l}0.17 \\
(0.03)\end{array}$ & 1.2 & 51 & 3.2 & $1.1(0.1)$ & $\begin{array}{l}1.3 \\
(0.10)\end{array}$ & 35 & 16 & $35(5)$ & 27 \\
\hline Filter 2 & $\begin{array}{l}11.1 \\
(0.13)\end{array}$ & $\begin{array}{l}0.7 \\
(0.05)\end{array}$ & $\begin{array}{l}0.11 \\
(0.02)\end{array}$ & 0.6 & 55 & 4.9 & $1.1(0.2)$ & $\begin{array}{l}1.3 \\
(0.05)\end{array}$ & 34 & 16 & $39(3)$ & 27 \\
\hline Filter 3 & $\begin{array}{l}11.1 \\
(0.16)\end{array}$ & $\begin{array}{l}0.4 \\
(0.07)\end{array}$ & $\begin{array}{l}0.16 \\
(0.01)\end{array}$ & 0.6 & 57 & 6.6 & $1.2(0.3)$ & $\begin{array}{l}1.0 \\
(0.06)\end{array}$ & 15 & 12 & $40(7)$ & 29 \\
\hline Filter 4 & $\begin{array}{l}11.0 \\
(0.16)\end{array}$ & $\begin{array}{l}0.3 \\
(0.11)\end{array}$ & $\begin{array}{l}0.15 \\
(0.05)\end{array}$ & 0.9 & 56 & 3.0 & $1.1(0.4)$ & $\begin{array}{l}1.0 \\
(0.26)\end{array}$ & 6 & 9 & $36(2)$ & 30 \\
\hline
\end{tabular}

$\mathrm{EMED}=$ Geometric mean of electric mobility equivalent diameter; $\mathrm{SEM}=$ scanning electron microscopy; $-=\mathrm{not}$ measured; $\mathrm{n}=32$ except ${ }^{\star} \mathrm{n}=6,+\mathrm{n}=1$.

Waters 616 pump, Waters 717 autoinjector, Waters $486 \mathrm{UV}$ detector at $365 \mathrm{~nm}$ and a Waters Millennium system for controlling the system and for evaluating the chromatograms was used.

Hydrocarbons - Two parallel air samples were collected in the exposure chamber on adsorbent tubes made of glass (Chrompack, length $160 \times 6 \mathrm{~mm}$ outer diameter, $3 \mathrm{~mm}$ inner diameter) packed with $90 \mathrm{mg}$ Tenax TA (Chrompack) and with silanised glass wool (Supelco) at both ends. Pumping the different air samples through the collecting tubes at $80-90 \mathrm{ml} / \mathrm{min}$ for 2 hours in the exposure chamber adsorbed the samples. The volatiles collected on the adsorbents were thermally desorbed with a Chrompack 16200 thermal desorption cold trap injector. The analyses of aliphatic (heptane, octane, nonane, decane, undecane, dodecane, and tetradecane including 2-butanone) and aromatic (benzene toluene, xylenes, and trimethylbenzenes) hydrocarbons were performed with thermal desorption-GC-MS. ${ }^{30}$

Ames test-Air samples were taken in the exposure chamber with a 2 hour sampling time, $20 \mathrm{~m}^{3} / \mathrm{h}$, and teflon coated glass fibre filters (diameter $125 \mathrm{~mm}$, Pallflex T60A20, Pallflex, USA) to collect particulate matter. Three situations were studied: unfiltered DDE (positive control), DDE filtered with four different cabin filter combinations, and air without any diesel exhaust (negative control).

The sampling filters were washed and dried before sampling as described previously. ${ }^{31}$ After particle collection the glass fibre filters were Soxhlet extracted with dichloromethane and the extract evaporated under reduced pressure and dissolved in dimethyl sulphoxide. Mutagenicity tests, in vitro, were carried out with Salmonella typhimurium strains TA98 and TA100 essentially according to Maron and Ames. ${ }^{32}$ A liver preparation from Aroclor-1254 treated male Sprague-Dawley rats was used as a metabolising system, S9. Each particulate extract was tested in triplicates in three concentrations corresponding to $0.325,0.65$, and $1.3 \mathrm{~m}^{3}$ air sample per plate.

\section{Automotive cabin air filter tests}

Volvo Gothenburg invited filter manufacturers to participate in a cabin air filter project in which cabin filters for particulate matter as well as hydrocarbons and inorganic gases were to be studied. According to the agreement with Volvo and the filter manufacturers, the different cabin filter compositions were unknown to us. A group at the Division of Technology, Ventilation, National Institute for Working Life measured and characterised the technical properties of various filters and the selection of the four different cabin filter combinations (table 1) used in this study was based on their results. The filter codes $6 \mathrm{C}, 7 \mathrm{~A}, 7 \mathrm{C}$, and $8 \mathrm{~A}$ are internal codes which will make it possible to compare our results of DDE with forthcoming papers published by other groups elsewhere. Filter 1 (7A) and filter 2 (6C) were particle filters. The combination filters (filter 3 and 4), used the particle filter $6 \mathrm{C}$ together with two different filters (7C and 8A) containing activated charcoal, which absorbs certain gaseous components. The combination filter 3 consisted of $6 \mathrm{C}+7 \mathrm{C}$ and filter 4 of $6 \mathrm{C}+8 \mathrm{~A}$, with the particle filter inserted upstream from the gas filter. The cabin filter combinations were inserted in a special filter frame $(200 \times 200$ $\mathrm{mm}$ ) $0.2 \mathrm{~m}$ before the entrance to the exposure chamber (fig 1). The DDE at $70 \mathrm{l} / \mathrm{s}$ passed through the different cabin filter combinations and this flow was kept constant by keeping the pressure drop (U tube manometer) across the iris diaphragm constant. If the flow changed by accumulation of diesel exhaust particles in the cabin filter, the flow was adjusted by the fan delivering air. A new cabin filter was inserted every day when the subjects were exposed to filtered exhaust.

\section{Symptoms}

The subjects were interviewed by a technician who registered the subjective symptoms according to a standardised questionnaire as previously presented..$^{18}$ The symptoms included the following: detection of an unpleasant smell, irritation in eyes, nose, throat and skin, fatigue, headache, cough, nausea, difficult breathing, tightness of the chest, bad taste in the mouth, and dizziness. They were scored from no symptoms (ranked 0) to maximal symptoms (ranked 11) according to a modified Borg scale $^{33}$ before exposure, at 15 and 30 minutes of exposure, and at the end of the exposure. The change in intensity of symptoms was calculated as the maximum score during exposure minus the score before exposure. 

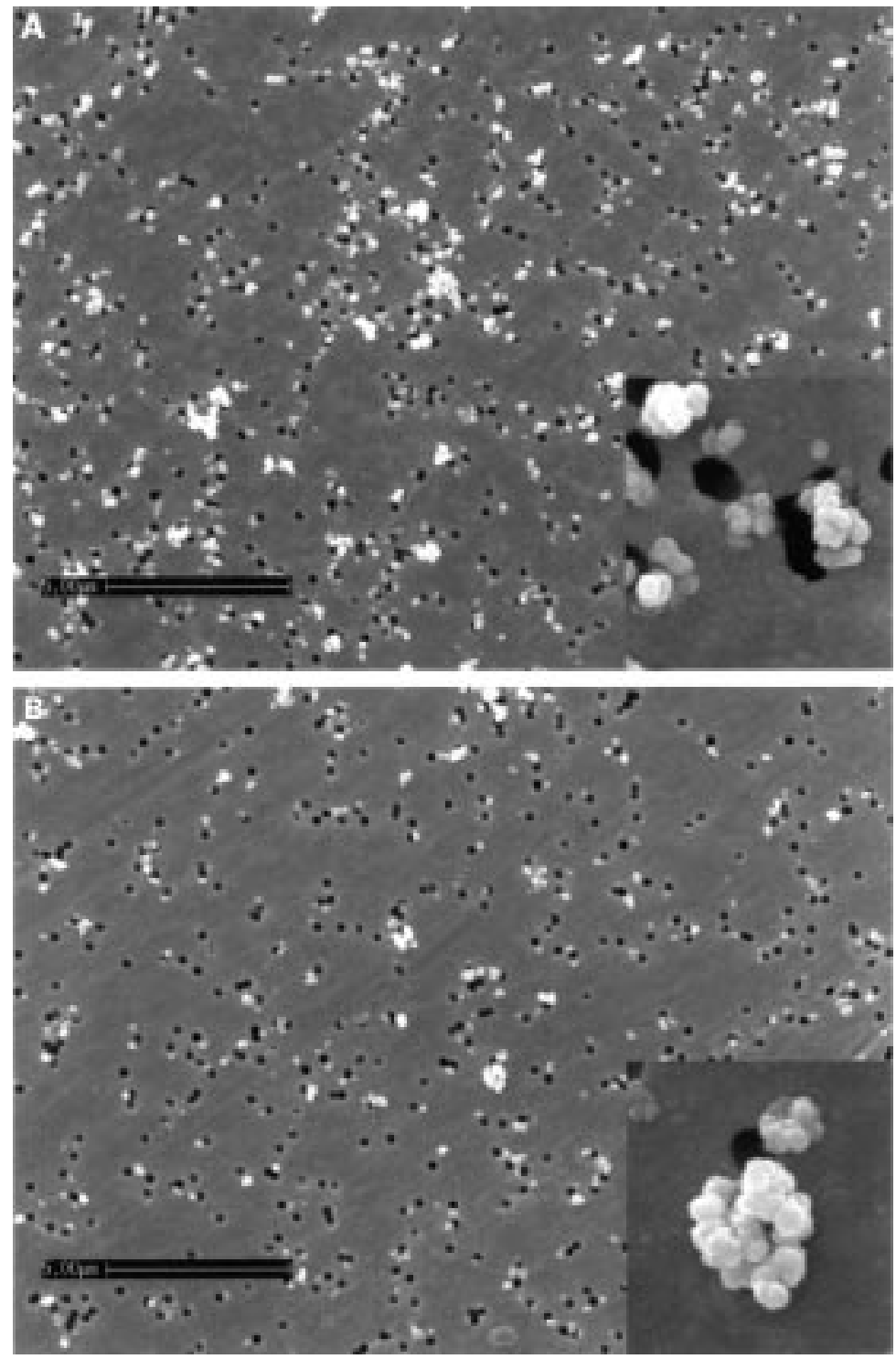

Figure 2 Diesel exhaust particles on Nuclepore filters seen through a scanning electron microscope and collected in the exposure chamber. White spots $=$ particles on the Nuclepore filters (grey), black spots $=$ holes in the Nuclepore filter. (A) Particles from unfiltered diluted diesel exhaust (DDE), and (B) particles filtered with particle and charcoal combination filter 4. (Insert) magnification 5 times primary image showing exhaust particle aggregates built up by smaller primary particles in the ultrafine range.

\section{Acoustic rhinometry}

Acoustic rhinometry was used to study if swelling of the nasal mucous membranes would occur causing nasal congestion. The volume of the nasal cavity was evaluated by acoustic reflection. ${ }^{34}$ The acoustic rhinometry apparatus (SRE-2100, Unoton AB, Stockholm, Sweden) includes a nose adapter (40 $\mathrm{mm}$ long), measuring tube (580 $\mathrm{mm}$ long) and computer system. The volumes of the right and left nasal cavity between 22 and $54 \mathrm{~mm}$ from the opening of each nostril were separately measured for each subject before and after each exposure. The volumes of the right and left nasal cavity were measured twice. The total measured volume of the nose was calculated by adding the mean volumes of the left and the right nostril. The change of total volume, which was the volume before exposure minus the volume after exposure, was calculated for each subject throughout the four cabin filter exposures, unfiltered DDE, and air exposure.

\section{Lung function test}

Forced expiratory flow for 1 second $\left(\mathrm{FEV}_{1}\right)$ and forced vital capacity (FVC) were measured before and after each exposure with a computerised pneumotachograph VitalographCompact. Volumes were given at body temperature and saturate pressure (BTPS).

\section{Nasal airway lavage}

Nasal airway lavage was performed before and after each exposure to evaluate early inflammatory responses in the nose. Saline solution (10 $\times 0.1 \mathrm{ml}$ ) was sprayed into one nostril and recovered in a sterile plastic cup. The procedure was repeated five times per nostril at each time point. After filtration through a nylon mesh the fluid was centrifuged at $4^{\circ} \mathrm{C}$. The supernatant was then immediately frozen for later analysis. With a Shandon Cytospin 4, cytospin preparations were performed after total cell counts had been determined with a Bürker chamber. The concentrations of neutrophils and eosinophils were measured and myeloperoxidase, interleukin- 8 and tryptase were analysed with commercially available radioimmunoassay (RIA) and enzyme linked immunosorbent assay (ELISA) kits (Pharmacia, $R$ and D). Interleukin-8 is an important neutrophil chemotaxic factor and myeloperoxidase is a marker of neutrophil activation, and tryptase is a marker for mast cell secretion.

\section{STATISTICS}

The SPSS for windows 6.0, module Wilcoxon's rank sum test was used for comparison between exposure systems and symptoms. Exposure effects in subjects were calculated as the maximum score during exposure minus the score before exposure. The mutagenicity evaluated by the Ames test was determined by regression analysis of the dose-response curve. The primary end points were defined initially to be the symptoms detection of an unpleasant smell and irritation of the eyes and nose, as based on earlier studies. A p value of $<0.05$ was considered significant.

Table 3 Genotoxic effects of different particulate samples from the exposure chamber on Salmonella typhimurium strains TA98 and TA100 (effects are given as the mean (SD) number of revertants $/ \mathrm{m}^{3}$ of air: the significance levels show the reduction in mutagenicity of the different filtered samples compared with the unfilterd diluted diesel exhaust (DDE) sample)

\begin{tabular}{lcccc}
\hline Sample types & Tester strain TA98-S9 & Tester strain TA98+S9 & Tester strain TA100-S9 & Tester strain TA100+S9 \\
\hline Air & $-2.4(2.8)$ & $-4.2(3.6)$ & $-7.5(16.8)$ & $-8.8(8.6)$ \\
DDE & $255.6(10.6)$ & $381.4(15.7)$ & $277.8(29.3)$ & $464.6(61.6)$ \\
Filter 1 & $49.1(4.9)^{\star \star \star}$ & $70.1(7.1)^{\star \star \star}$ & $34.2(14.7)^{\star \star \star}$ & $124.9(14.5)^{\star \star \star}$ \\
Filter 2 & $114.0(7.9)^{\star \star \star}$ & $186.1(8.1)^{\star \star \star}$ & $172.0(16.3)^{\star \star}$ & $272.4(18.7)^{\star \star}$ \\
Filter 3 & $103.9(12.2)^{\star \star \star}$ & $170.7(8.7)^{\star \star \star}$ & $118.1(10.8)^{\star \star \star}$ & $232.6(13.8)^{\star \star}$ \\
Filter 4 & $183.1(4.6)^{\star \star \star}$ & $236.5(13.0)^{\star \star \star}$ & $162.0(20.3)^{\star \star}$ & $366.6(18.1) \mathrm{NS}$ \\
\hline
\end{tabular}

${ }^{\star} \mathrm{p}<0.05 ;{ }^{\star \star} \mathrm{p}<0.01 ;{ }^{\star \star \star} \mathrm{p}<0.001$. 

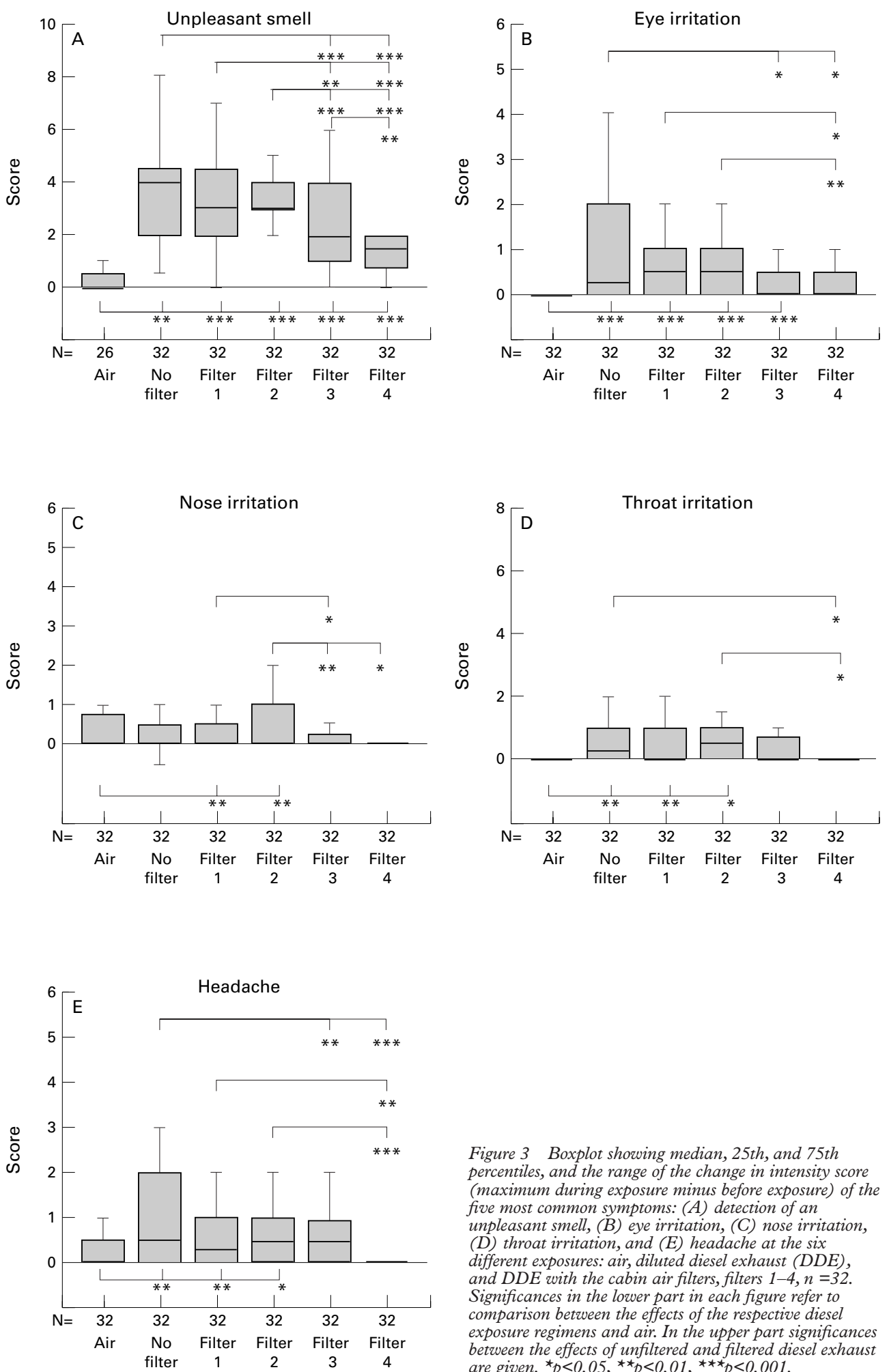

Figure 3 Boxplot showing median, 25th, and 75th percentiles, and the range of the change in intensity score (maximum during exposure minus before exposure) of the five most common symptoms: $(A)$ detection of an unpleasant smell, (B) eye irritation, $(C)$ nose irritation, (D) throat irritation, and (E) headache at the six different exposures: air, diluted diesel exhaust (DDE), and $D D E$ with the cabin air filters, filters $1-4, n=32$. Significances in the lower part in each figure refer to comparison between the effects of the respective diesel exposure regimens and air. In the upper part significances between the effects of unfiltered and filtered diesel exhaust are given. ${ }_{p}<<0.05,{ }^{\star *} p<0.01,{ }^{\star *} p<0.001$.

Results

Exposure data and data from the additional filter tests are given in table 2 . All four filter combinations reduced exposure concentrations of particle mass and particle number, concentrations of particles (by scanning electron microscope) $\geqslant 0.4 \mu \mathrm{m}$, and total aromatics, compared with DDE. Filters 3 and 4, which are combination filters with charcoal, reduced

$\mathrm{NO}_{2}, \mathrm{HCs}$, and total aliphatics, compared with DDE. The submicron aerosol size of diesel exhaust measured as electrical mobility equivalent diameter, $\mathrm{CO}$, formaldehyde, and acetaldehyde were not affected by the various cabin filters, compared with DDE. With filter 4 the concentration of total aliphatics and aromatics were at the same level as in air. All samples of HCs contained mainly aliphatic and aromatic 
HCs $\left(\mathrm{C}_{6}\right.$ to $\left.\mathrm{C}_{19}\right)$ including toluene, ethylbenzene, xylenes, and trimethylbenzenes (data are not shown).

SCANNING ELECTRON MICROSCOPE

No particles could be detected on the Nuclepore filter in air from the chamber, and on the other samples including DDE and the four filter combinations, the particles were evenly distributed. The number of particles $\geqslant 0.4 \mu \mathrm{m}$ in unfiltered DDE and DDE with filters 1-4 are shown in table 2. All filter combinations reduced the number of particles compared with DDE. Scanning electron microscope images of particles from DDE and DDE with the filter combination 4 are shown in figure 2 . The larger particle aggregates were built up by smaller primary particles in the ultrafine range as seen in figure 2 .

AMES TEST

The data in table 3 show that air in the exposure chamber did not give any significant mutagenic effects in the Salmonella tester strains. All DDE and all filter combinations with and without $S 9$ had a significantly higher mutagenic effect than air (data are not shown). Unfiltered DDE gave the highest mutagenic effect and all DDE samples gave a higher mutagenic effect in the presence of S9 than in its absence. Furthermore all the cabin filters reduced the mutagenicity significantly compared with DDE in both strains in the absence of S9 and all samples but one (filter 4 on TA100+S9) in the presence of a metabolising system with and without S9. The lowest mutagenic effect was seen with the particulate filter 1.

EFFECTS IN HUMANS

The difference between maximum intensity during exposure and before exposure of the most prominent symptoms, detection of an unpleasant smell, irritation of the eyes, nose, and throat, and headache at the six exposures including air, DDE, and DDE with the different cabin filter combinations are shown in figure 2. Significant differences were found for the combination filters with charcoal, filter 3 and filter 4 versus unfiltered DDE and in some instances also filters 1 and 2 .

Results from acoustic rhinometry, FVC, $\mathrm{FEV}_{1}$, total eosinophil and neutrophil number, myeloperoxidase, interleukin-8, and tryptase were not significantly different between unfiltered DDE and DDE combined with the four different cabin filters or air (data not shown). There were no significant differences between allergic and non-allergic subjects or between bus drivers and students.

\section{Discussion}

Air pollution and, in particular, particulate pollutants have been strongly associated with adverse health effects. Diesel exhaust is an example of combined particulate and gaseous pollutants known to elicit mucosal symptoms and headache and also to provoke airway inflammation locally in the bronchial mucosa. ${ }^{17-21}$ Among the many strategies to intervene and reduce unwanted effects of diesel exhaust, it is possibile to use more efficient automotive cabin air filters to reduce or prevent exhaust components from entering the driver cabin, and thereby reduce the exposure in those people travelling or working within the vehicle. In this study it was shown that the use of particle filters 1 and 2, decreased diesel exhaust particle mass by about half, but did not reduce the symptoms induced by the exhaust. Interestingly the addition of active charcoal filters to a particle filter significantly reduced the discomfort caused by the exhaust exposure. This was associated with filter reduction of gaseous components, especially HCs.

Diesel exhaust is a complex mixture of inorganic gases, HCs, and particles. The particulate concentration used for 1 hour of chamber exposure to unfiltered diluted diesel exhaust in this study was about $300 \mu \mathrm{g} / \mathrm{m}^{3}$. Occupational exposure to diesel exhaust particles in enclosed spaces - such as mines with heavy duty diesel engines - have been reported to be up to 1700 $\mu \mathrm{g} / \mathrm{m}^{3} .^{35}$ The $\mathrm{PM}_{10}$ in a Swedish city road tunnel was reportedly $300-500 \mu \mathrm{g} / \mathrm{m}^{3}$ during 1 hour measurements, with peak concentrations up to $1990 \mu \mathrm{g} / \mathrm{m}^{3} .^{36}$ Many of the world's mega-cities have annual average concentrations of suspended particulate matter in the range of 200$600 \mu \mathrm{g} / \mathrm{m}^{3}$ with peak concentrations $>1000$ $\mu \mathrm{g} / \mathrm{m}^{3} .^{137}$ These concentrations were commonly measured high above the ground on rooftops. The traffic and curbside concentrations may be considerably higher. ${ }^{38}$ The composition of ambient particulate matter varies depending on contribution from different sources. It has been calculated that $89 \%$ of the anthropogenic emissions of $\mathrm{PM}_{10}$ in Los Angeles was coming from different forms of transport. ${ }^{39}$ As diesel engines may produce up to 100 times more particles than a gasoline powered engine a large proportion of the particles in ambient air has been estimated to be of diesel engine origin.

The $\mathrm{NO}_{2}$ concentration for unfiltered diesel exhaust in this study was $0.7 \mathrm{ppm}$, which is a high traffic concentration. ${ }^{36}$ This may be greatly exceeded in certain workplaces with diesel engines. The ability of the combination filters 3 and 4 to significantly reduce the $\mathrm{NO}_{2}$ concentration was shown. Even though $\mathrm{NO}_{2}$ has clearly been associated with certain adverse health effects, in the experience of this and other groups, it has not been shown that this component would be responsible for the symptoms found.

Recording symptoms has proved to be very useful when studying the effects of diesel exhaust, as recently reported by this group. ${ }^{17} 1825$ The most common symptoms during controlled diesel exhaust exposures as well as in traffic and workplaces, are a detection of an unpleasant smell; irritation of the eyes, nose, and throat; and headache. As reported earlier, the use of the modified Borg scale has been shown to be an efficient way of grading and distinguishing changes in symptoms during exposure to diesel exhaust. ${ }^{17}{ }^{18}$ In the present study, recording symptoms discriminated the efficiency between filters compared 
with unfiltered DDE and air. Most symptoms were significantly higher during the exposure to diesel exhaust than during exposure to air. The use of filter 1 and 2 (particle filters only) substantially reduced the particle mass by about half, although this was not associated with any decrease of the symptoms induced by diesel exhaust. This is in agreement with two recent studies evaluating intervention of diesel exhaust effects with a ceramic particle trap at the end of the tail pipe of a diesel engine. It was reported that a similar reduction of particles by half did not reduce symptoms, bronchoconstriction, or indices of airway inflammation reflected in bronchoalveolar lavage fluid in healthy humans. ${ }^{18}{ }^{21}$ The low efficiency of the particle filters 1 and 2 differs from the higher efficiency of filters 3 and 4 (particle filter and charcoal filter combinations), in reduction of symptoms. Interestingly, filters 3 and 4 reduced nose irritation and throat irritation to levels that were not significantly different from those during exposure to air. The efficiency of filter 4 seems to be the higher of the two, with nose and throat irritation and headache at or below during exposure to air. Filter 4 also produced significantly lower detection of an unpleasant smell than did the other particle and charcoal filter combination (filter 3).

The efficiency of the filters to reduce the measured aliphatics and aromatics might be associated with their effectiveness in reducing symptoms. When considering this it should be recalled that the more detailed analyses of hydrocarbons were based on few measurements. This was due to the complexity and cost for these measurements. Filter 4, which seems to be better at reducing symptoms, was also by far the most effective in reducing total aliphatics and aromatics down to concentrations found in air. The second most effective filter in reducing symptoms and $\mathrm{HCs}$ was the combination filter 3 . The particle filters 1 and 2 were not very efficient in reducing aliphatics whereas the decrease in total aromatics was more pronounced, although not as good as for the combined particle and active charcoal filters 3 and 4 . As the ability to reduce symptoms between the combination filters and particle filters seems to be related to their ability to reduce total aliphatics, it is tentatively proposed that total aliphatics may be important in the production of symptoms, especially detection of an unpleasant smell.

The study was primarily directed to investigate the effects on acute symptoms, but also included several secondary variables. Those were included to evaluate whether any major local effects could be found early after exposure. No changes in acoustic rhinometry could be found suggesting that at the time of investigation early after exposure, there was no detectable swelling of the nasal mucosa after exposure. Measurements of inflammatory markers and cells in nasal airway lavage fluid before and immediately after exposure to diesel exhaust did not show any signs of acute nasal inflammatory response. It cannot currently be excluded that recordable effects may have developed later after exposure. Due to the complexity of the expo- sures with many subjects, it was not within our capability to have nasal lavages later after exposure. Possible later nasal inflammatory events induced by diesel exhaust are currently being investigated in a separate project. Diesel exhaust has in several studies by this group been shown to be a strong proinflammatory stimulant. The exhaust may cause an inflammatory cell infiltration in the bronchial epithelial mucosa involving mast cells, neutrophils, and various lymphocyte subsets, together with enhanced expression of the vascular, endothelial adhesion molecules ICAM-1 and VCAM-1 in the submucosa at 6 hours after exposure to diesel exhaust with particle concentrations of $300 \mu \mathrm{g} / \mathrm{m}^{3}$ for 1 hour. ${ }^{20}$ This was accompanied by mast cell degranulation and fibronectin secretion in bronchoalveolar lavage fluid. Furthermore exposure to diesel exhaust may induce reduced alveolar macrophage phagocytosis in vitro. ${ }^{19}{ }^{21}$ In a study designed primarily to evaluate changes in lung function it was shown that exposure to DDE does induce a bronchoconstrictive response as reflected by measurements of airway resistance with a whole body plethysmograph.$^{18}$ In the current study only dynamic spirometry was included, which is less sensitive, and no acute changes were found for the variables $\mathrm{FEV}_{1}$ and FVC in the healthy subjects.

There was no difference between responses induced by diesel exhaust in the professional drivers and the student volunteers. This suggests that, at least for the variables investigated, professional drivers do not seem to be more responsive due to their frequent exposure. In an earlier study investigating biomedical effects of the addition of a green colour to untaxed and non-coloured diesel fuel in Sweden, it was suggested that professional drivers of forest harversters and forwarders tended to be more responsive than students. ${ }^{25}$ Whether that was a finding that only referred to that specific group of drivers is inconclusive. Another finding was that within the frame of the study, subjects with allergic rhinoconjunctivitis were not more sensitive to diesel exhaust.

Genotoxicity from diesel exhaust from long term exposure is an issue of interest. This has been considered in retrospective epidemiological studies as well as long term animal experiments. For obvious reasons it was not possible to study this experimentally in humans, and the exposure doses given to the subjects in this study are minuscule compared with what people are exposed to during their lifetime in outdoor air or workplaces. A common in vitro model was used to evaluate genotoxicity of complex mixtures - such as diesel exhausts is the Ames test. This was performed on particles collected only once from each exposure system, due to limited resources. The results obtained may therefore give indications, rather than proof, of the filter efficacy. By contrast with the measurement of symptoms, the addition of active charcoal to particulate filters, as in filters 3 and 4, did not meet with success. They were not apparently more effective than the particle filter 2 in reducing mutagenicity. It should be borne in mind, however, that only the particulate phase and neither semivolatile 
nor gaseous components were tested in this case. Interestingly, particle filter 1, which seemed to be not as efficient as filter 2 in reducing particle mass and particle number, was clearly best in the Ames test. This may have been due to interaction of particle filter 1 with the exhaust particles and the components adsorbed to their surfaces. Further investigation is needed to produce more detailed information of amounts of many HCs with different genotoxic properties, to clarify exactly which HCs the filter may have reduced to give its good efficiency. As this large study included 192 exposures, with prestudy days for all people, it was not feasible also to evaluate particle filter 1 with different charcoal filters. An interesting question that remains to be studied is whether the combination of the efficiency of particle filter 1 to reduce mutagenicity could be teamed up with the efficiency from a charcoal filter to reduce symptoms, to give an even better combination filter than filter 4 .

The exposure system and the use of automotive cabin air filters have shown that the intervention with experimental filter products may indeed reduce certain biological events. From earlier studies it was estimated that acute subjective symptoms, measured under controlled circumstances with the modified Borg scale and within a proper study design, would be the most sensitive possible biomarker of acute effects of diesel exhaust to measure in a large scale study necessary to evaluate several different exposure situations. More invasive techniques to evaluate adverse biological events within the airways such as bronchoscopies with bronchoalveolar lavages and sampling of bronchial mucosal biopsies have proved very sensitive and accurate to describe inflammatory events and mechanisms. Obviously this kind of invasive technique can only be used on a smaller scale than was needed to consider the current questions of efficiency of several filters, compared with DDE and air.

It is concluded that the investigated particle filters were, as expected, able to reduce diesel exhaust particles, but surprisingly without any significant reduction in the intensity of symptoms in the exposed people. By contrast, the addition of active charcoal filters, to a particle filter, clearly reduced symptoms induced by diesel exhaust. The biggest differences in efficacy between the filters were in the reduction of detection of an unpleasant smell from the diesel exhaust. Even the efficacy of the two charcoal filter combinations differed significantly. The ability to reduce symptoms may depend upon the abilities of the filter to reduce certain HCs. Complementary studies on vehicle cabin air filters may result in further diminishing biomedical effects of diesel exhaust in subjects exposed in traffic and workplaces.

We acknowledge the following people and institutions. Volunteers, bus drivers, Kjell Englund, Ulf Hammarström, Maj-Cari Ledin, Gerd Lindén, Jamshid Pourazar, Lena Skedebrant, and Helen Burström; Stefan Frisk, Kjell Holmgren, Tage Norén, and Jan Forsén at the Swedish Machinery Testing Institute, and Jan Forsén at the Swedish Machinery Testing Institute, Nordlund, Polarbuss Trafik AB, Umeå; Magdalena Friström, Nordlund, Polarbuss Trafik AB, Umeå; Magdalena Friström, Mätforum AB, Stockholm; statistician Anders Magnuson, Department of Occupational and Environmental Medicine,
Centre for Public Health Sciences, Linköping; Christer Lindman, Holmsund, and Lennart Schönning, Stockholm both at Preem Petroleom AB, Mats Bende, Department of Otorhinolaryngology, Kärnsjukhuset, Skövde; Jan-Olov Hjortsberg, VME Industries Sweden AB, Eskilstuna; Christer Eriksson Volvo Truck Corporation, Gothenburg; and Staffan Krantz, Lars Olander, Anders Jansson, and Johan Johansson at Division of Technology, Ventilation, National Institute for Working Life, Solna, Sweden; Hans-Georg Horn, TSI GmbH, Aachen, Germany; and Tylir Beck, TSI Incorporated, St Paul, MN, USA. Swedish Council for Work Life Research, Stockholm, Sweden. The study was primarily supported by a grant from the Swedish National Board for Industrial and Technical Development (NUTEK), Stockholm, Sweden
nological Development, Gothenburg, Sweden.

1 Air pollution of the worlds megacities. A report from the UN Environment Programme and WHO. Environment 1994;36:5-37.

2 Seaton A, Mac Nee W, Donaldson K, et al. Hypothesis: particulate air pollution and acute health effects. Lancet 1995; 345:176-8.

3 Ostro B. The association of air pollution and mortality: examining the case for inference. Arch Environ Health 1993;48:336-42.

4 Dockery DW, Pope A 1ll, Xu X, et al. An association between air pollution and mortality in six US cities. $N$ Engl f Med 1993;329:1753-9.

5 Schwartz J. Air pollution and daily mortality in Birmingham, Alabama. Am f Epidemiol 1993;137:1136-47.

6 Schwartz J, Dockery DW. Particulate air pollution and daily mortality in Steubenville, Ohio. Am $\mathcal{F}$ Epidemiol 1992;135: 12-19.

7 Dockery DW, Pope CA 11l. Acute respiratory effects of particulate air pollution. Ann Rev Public Health 1994;15:107 32 .

8 Wordley J, Walters S, Ayres JG. Short term variations in hospital admissions and mortality and particulate air pollution. Occup Environ Med 1997;54:108-16.

9 Abbey DE, Ostro BE, Petersen F, et al. Chronic respiratory symptoms associated with estimated long-term ambient concentrations of fine particulates less than $2.5 \mu \mathrm{m}$ in aerodynamic diameter $\left(\mathrm{PM}_{25}\right)$ and other air pollutants. Fournal of Exposure Analysis and Environmental Epidemiology 1995; 5:137-59

10 Oberdörster G, Ferin J, Gelein R, et al. Role of alveolar macrophage in lung injury: studies with ultra fine particles. Environ Health Perspect 1992;97:193-9.

11 Reger R, Hancock J, Hankinson J, et al. Coal miners exposed to diesel exhaust emissions. Ann Occup Hyg 1982;26:799815.

12 Gamble J, Jones W, Minshall S. Epidemiologicalenvironmental study of diesel bus garage workers: acute effects of $\mathrm{NO}_{2}$ and respirable particulate on respiratory system. Environ Res 1987;42:201-14.

13 Ayres SM, Evans R, Licht D, et al. Health effects of exposure to high concentrations of automotive emissions. Arch Environ Health 1973;27:168-78.

14 Ulfvarson U, Alexandesson R, Aringer L, et al. Effects of exposure to vehicle exhaust on health. Scand $\mathcal{F}$ Work Environ Health 1987;13:505-12.

15 Ulfvarson U, Alexandersson R. Reduction in adverse effect on pulmonary function after exposure to filtered diesel exhaust. Am f Ind Med 1990;17:341-7.

16 Ulfvarson U, Alexandersson R, Dahlqvist M, et al. Pulmonary function in workers exposed to diesel exhausts: the effect of control measures. Am ₹ Ind Med 1991;19:283-9.

17 Rudell B, Sandström T, Hammarström U, et al. Evaluation of an exposure setup for studying effects of diesel exhaust in humans. Int Arch Environ Health 1994;66:77-83.

18 Rudell B, Ledin M-C, Hammarström U, et al. Effects on symptoms and lung function in humans experimentally exposed to diesel exhaust. Occup Environ Med 1996;53: 658-62.

19 Rudell B, Sandström T, Stjernberg N, et al. Controlled diesel exhaust exposure in an exposure chamber: pulmonary Aerosol Science 1990;21(suppl 1):411-4.

20 Salvi S, Blomberg A, Rudell B, et al. Acute inflammatory responses in the airways and peripherial blood following short term exposure to diesel exhaust in healthy human volunteers. Am f Respir Crit Care Med (in press).

21 Rudell B, Blomberg A, Helleday R, et al. Bronchoalveolar inflammation following exposure to diluted diesel exhaust: comparison between unfiltered and particle trap filtered exhaust. Occup Environ Med 1999 (in press)

22 Blomberg A, Sainsbury CG, Rudell B, et al. Nasal cavity lining fluid ascorbic acid concentration increases in healthy human volunteers following short term exposure to diesel exhaust. Free Radic Res 1998;28:59-67.

23 Diaz-Sanchez. The role of diesel exhaust particles and their associated polyaromatic hydrocarbons in the induction of allergic airway disease. Allergy 1997;52 (suppl 38):52-6.

24 Sandström T, Blomberg A, Helleday R, et al. Air pollution effects on on allergen responses: experiences from animal studies. Eur Respir Rev 1998;8:168-74.

25 Nilsson C-A, Andersson K, Andersson B, et al. Slutrapport: akuta retbesvär av avgaser från grönfärgad och ofärgad dieselolja. Grön diesel - miljö- och hälsorisker. Stockholm: Fritzes, Customer Services, Swedish Official Government Fritzes, Customer Services, Swedish Official Government
Reports, 1995;3:1-70. (In Swedish with English summary.) 
26 Levin JO, Lindahl R, Andersson KA. A passive sampler for formaldehyde in air using 2,4-dinitrophenylhydrazinecoated glass fibre filters. Environ Sci Technol 1986;20:1273-6. 27 Hörstedt P, Danielsson A, Nyhlin H, et al. Adhesion of bacteria to the human small

28 Levin J-O, Lindahl R, Andersson K. High-performance liquid-chromatographic determination of formaldehyde in air in the PPB to PPM range using diffusive sampling and hydrazone formation. Environ Technol Lett 1988;9:1423-30.

29 Lindahl R, Levin J-O, Mårtensson M. Validation of a diffusive sampler for the determination of acetaldehyde in air. Analyst 1996;121:1177-81.

30 Sunesson A-L, Nilsson C-A, Andersson B, et al. Thermal desorption cold trap-injection in high-resolution gas chromatography: multivariate optimization of experimental conditions. f Chromatogr 1992;623:93-103. 31 Westerholm R, Almén J, Li HR, et al. Chemical and biological characterization of particulate, semivolatile, and gas phase associated compounds in diluted heavy duty diesel exhausts: a comparison of three different sem

32 Maron DM, Ames BN. Revised methods for the Salmonella mutagenicity test. Mut Res 1983;113:173-215.
33 Borg GAV. Psycophysical bases of perceived exertion. Med Sci Sports Exerc 1982;14:377-81.

34 Hilberg O, Jackson AC, Swift DL, et al. Acoustic rhinometry: evaluation of nasal cavity geometry by acoustic reflection. F Appl Physiol 1989;66:295-303.

35 Ambs JL, Cantrell BK, Watts WF, et al. Evaluation of disposable diesel exhaust filter for permissible mining machines. Pittsburgh, PA: Bureau of Mines, 1994. (RI 9508.)

36 Olander L. Luftföroreningar i fordon: halter och åtgärder (Air pollution in vehicle cabins). Arbete Och Hälsa 1996;18: 1-42. (English summary.)

37 Kalandidi A, Gratziou Ch, Katsouyanni K, et al. Air pollution and respiratory health of children: the PEACE panel study in Athens, Greece. Eur Respir Rev 1998;8:11724

38 Watt $\mathrm{M}$, Godden $\mathrm{D}$, Cherrie J, et al. Individual exposure to particulate air pollution and its relevance to thresholds for health effects: a study of traffic wardens. Occup Environ Med 1995;52:790-2.

39 Southern California Association of Governments. South Coast Air Quality Management District, Air Quality Management Plan: South Coast Air Basin. Los Angeles, CA: SCAG, 1991.

\section{Vancouver style}

All manuscripts submitted to Occup Environ Med should conform to the uniform requirements for manuscripts submitted to biomedical journals (known as the Vancouver style.)

Occup Environ Med, together with many other international biomedical journals, has agreed to accept articles prepared in accordance with the Vancouver style. The style (described in full in the $F A M A[1]$ ) is intended to standardise requirements for authors, and is the same as in this issue.

References should be numbered consecutively in the order in which they are first mentioned in the text by Arabic numerals on the line in square brackets on each occasion the reference is cited (Manson[1] confirmed other reports[2][3][4][5]). In future references to papers submitted to Occup Environ Med should include: the names of all authors if there are three or less or, if there are more, the first three followed by et al; the title of journal articles or book chapters; the titles of journals abbreviated according to the style of Index Medicus; and the first and final page numbers of the article or chapter. Titles not in Index Medicus should be given in full.

Examples of common forms of references are:

1 International Committee of Medical Journal Editors. Uniform requirements for manuscripts submitted to biomed journals. ЭAMA 1993;269:2282-6.

2 Soter NA, Wasserman SI, Austen KF. Cold urticaria: release into the circulation of histmaine and eosinophil chemotactic factor of anaphylaxis during cold challenge. N Engl F Med 1976;294:687-90.

3 Weinstein L, Swartz MN. Pathogenic properties of invading micro-organisms. In: Sodeman WA Jr, Sodeman WA, eds. Pathologic physiology, mechanisms of disease. Philadelphia: W B Saunders, 1974:457-72. 